Gut, 1971, 12, 973-977

\title{
The effect of fat on calcium absorption from a mixed meal in normal subjects, patients with malabsorptive disease, and patients with a partial gastrectomy
}

\author{
J. E. AGNEW AND C. D. HOLDSWORTH ${ }^{1}$
}

From the Department of Physics, Royal Free Hospital, London, and the Department of Gastroenterology, St Leonard's Hospital, London, and St Bartholomews' Hospital, London

SUMMARY The absorption of ${ }^{47} \mathrm{Ca} \mathrm{Cl}_{2}$ taken with a milk and porridge meal was measured in normal subjects, patients with a partial gastrectomy, and patients with malabsorption. The addition of palm oil to the meal depressed calcium absorption, whereas the addition of medium-chain triglyceride had no effect. The contrasting effect of the two fats on calcium absorption was most marked in patients with a partial gastrectomy and least marked in patients with malabsorption. In patients with malabsorption, impairment of calcium absorption was most marked in the patients with a significant increase in faecal fat excretion. Absorption of calcium was greater in patients with a partial gastrectomy than in normal subjects.

Very little information is available on the effect of fat on calcium absorption in man, although it has often been suggested that in steatorrhoea calcium malabsorption may be due in part to the precipitation of insoluble calcium soaps in the intestinal lumen (Steggerda and Mitchell, 1951). If this were the case, then substitution of medium-chain triglycerides for long-chain triglycerides in the diet might improve calcium absorption, especially as in both normal and bile-duct-obstructed rats medium-chain triglycerides stimulate calcium absorption (Kehayoglou, Williams, Whimster, and Holdsworth, 1968). We have therefore compared the effect of feeding medium-chain triglycerides with that of feeding long-chain triglycerides on the absorption of calcium in normal human subjects, in patients with partial gastrectomy, and in patients with various types of malabsorption.

\section{Materials and Methods}

All subjects were fasted for eight hours before the test. No attempt was made to standardize their previous calcium intake, and their normal diet was continued between the tests. Of the 15 control subjects some suffered from a variety of medical conditions, none of which would be likely to affect absorption. The 17 gastrectomized subjects had

'Present address: Clinical Research Institute, The Royal Infirmary. Sheffield.

Received for publication 17 September 1971. undergone either Billroth I or Polya gastrectomy from one to 20 years previously. Neither age, interval after operation, nor type of operation was found to affect the results, and all patients after gastrectomy are therefore considered as a single group. None had anaemia at the time of studies or had clinical evidence of malabsorption. The patients with malabsorptive states had been diagnosed by standard methods, including in all patients estimation of faecal fat and xylose absorption, jejunal biopsy, and radiological studies.

Calcium absorption was measured by determining, using a whole body counter, the amount of ${ }^{47} \mathrm{Ca}$ retained in the body seven days after ingestion. Plasma ${ }^{47} \mathrm{Ca}$ in the blood three hours after ingestion, although a less direct measure of absorption, was also determined as a check on the whole body counter results. These methods have been described in detail elsewhere (Agnew, Kehayoglou, and Holdsworth, 1969). A milk drink containing $100 \mathrm{mg}$ of calcium was prepared by reconstituting $8 \mathrm{~g}$ of powdered milk to $85 \mathrm{ml}$ with distilled water, and 10 microcuries of ${ }^{47} \mathrm{Ca}$ as $\mathrm{CaCl}_{2}$ were added approximately 18 hours before administration. This was taken with a standard cooked porridge prepared by adding $14 \mathrm{~g}$ of porridge oats and $1 \mathrm{~g}$ of sodium chloride to $200 \mathrm{ml}$ of distilled water. The porridge was prepared in bulk and kept deep frozen in aliquots until shortly before administration. To study the influence of different fats on calcium absorption, the meal was given mixed either 


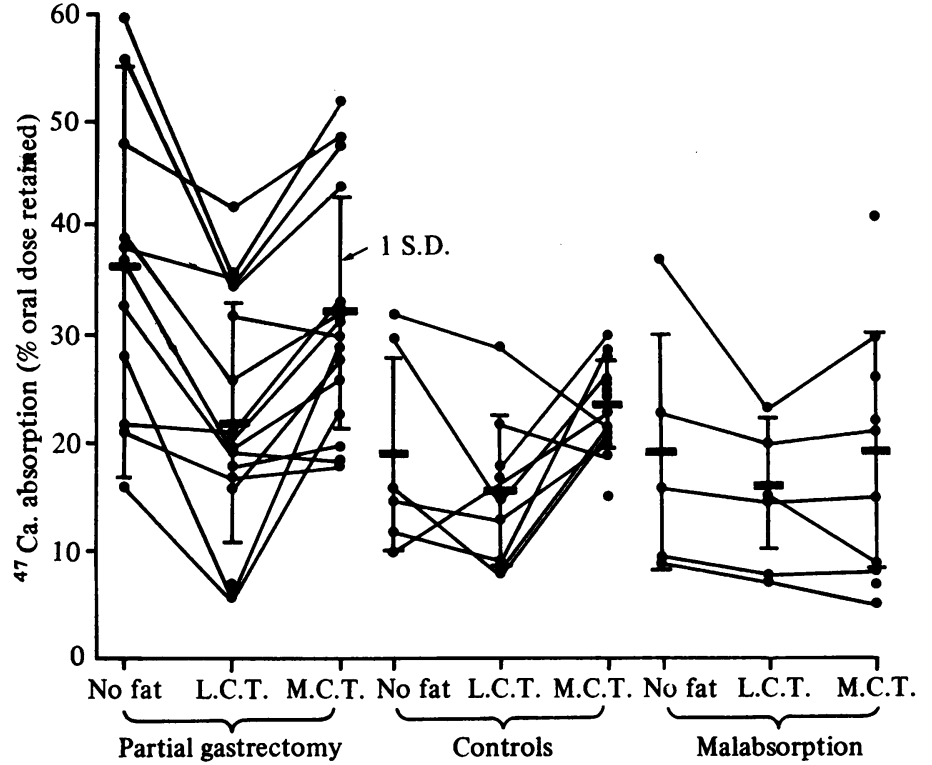

Fig. 1 Absorption of ${ }^{47} \mathrm{Ca}$ measured by whole body counter from subjects after a milk and porridge breakfast taken either alone, with added medium-chain triglyceride (MCT), or with added long-chain triglyceride (LCT). with $30 \mathrm{~g}$ of specially prepared refined deodorized fully hardened palm oil or $30 \mathrm{~g}$ of medium-chain triglyceride. Gas liquid chromatography analysis of the palm oil showed a fatty acid composition of $\mathrm{C}_{14: 0}$ (myristic) 1\%, $\mathrm{C}_{16: 0}$ (palmitic) $43.4 \%, \mathrm{C}_{18: 0}$ (stearic) $51 \cdot 3 \%$, and $\mathrm{C}_{18: 1}$ (oleic) $2 \cdot 9 \%$. Analysis of the medium-chain triglyceride showed the fatty acids to be mainly $\mathrm{C}_{8: 0}$ (octanoic) $71 \%$ and $\mathrm{C}_{10: 0}$ (decanoic) $23 \%$ with less than $3 \%$ of acids with a chain length of less than $\mathrm{C}_{8}$ or more than $\mathrm{C}_{10}$. Apart from the fat content the composition of all the meals was identical. The calorific value of the meal with no added fat was estimated as 160 , and this was increased to 410 by adding medium-chain triglyceride or 432 by adding long-chain triglyceride.

Absorption was studied, as far as possible, from different meals in the same subject. The extent to which this was possible is indicated in Figure 1.

\section{Results}

The individual and mean values for absorption from each type of meal are shown in Fig. 1 and Table $\mathbf{I}$. In each group of subjects absorption from the meal containing medium-chain triglyceride was similar to that from the meal containing no added fat. In contrast, long-chain triglyceride depressed calcium absorption. Taking all three groups of subjects together, this depression was highly significant when assessed by a paired $t$ test $(n=21, t=5.53$, $P<0.001$ ). Taking the groups separately, depression of calcium absorption by the long-chain triglyceride was found to be significant in patients with a partial gastrectomy $(\mathrm{n}=11, \mathrm{t}=5.44, \quad \mathrm{P}<0.001)$ but failed to reach significance in normal subjects $(n=5$, $t=2.54)$ and patients with malabsorption $(n=5$, $t=1 \cdot 73$ ).

Taking all three groups of patients together, calcium absorption was significantly better from the meal mixed with medium-chain triglyceride than from the long-chain triglyceride meal $(n=29, t=$ $4.81, P<0.001$ ). This difference in absorption from the two meals was significant both in normal subjects $(\mathrm{n}=8, \mathrm{t}=2.48, \mathrm{P}<0.05)$ and patients with partial

\begin{tabular}{|c|c|c|c|c|c|c|}
\hline \multirow[t]{2}{*}{ Type of Meal } & \multicolumn{3}{|c|}{ Absorption by Whole-body Count ( $\%$ retention) } & \multicolumn{3}{|c|}{ Three-hour Plasma ${ }^{47} \mathrm{Ca}(\%$ dose/litre of plasma $)$} \\
\hline & Control Subjects & $\begin{array}{l}\text { Partial } \\
\text { Gastrectomy }\end{array}$ & Malabsorption & Control Subjects & $\begin{array}{l}\text { Partial } \\
\text { Gastrectomy }\end{array}$ & Malabsorption \\
\hline $\begin{array}{l}\text { No added fat } \\
\text { + Palm oil } \\
\text { + Medium-chain } \\
\text { triglyceride }\end{array}$ & $\begin{array}{l}19.2 \pm 9.4(6) \\
15.5 \pm 6.9(9) \\
23.4 \pm 4.1(14)\end{array}$ & $\begin{array}{l}36 \cdot 1 \pm 14 \cdot 3(11) \\
21 \cdot 7 \pm 11 \cdot 2(16) \\
32 \cdot 1 \pm 10 \cdot 8(16)\end{array}$ & $\begin{array}{l}19 \cdot 2 \pm 11 \cdot 3(5) \\
15 \cdot 9 \pm 6 \cdot 1(7) \\
19 \cdot 1 \pm 11 \cdot 1(10)\end{array}$ & $\begin{array}{l}1.8 \pm 0.9(6) \\
1.4 \pm 0.6(9) \\
1.9 \pm 0.6(14)\end{array}$ & $\begin{array}{l}2.1 \pm 1 \cdot 1(11) \\
1.5 \pm 0.6(16) \\
2.3 \pm 0.75(16)\end{array}$ & $\begin{array}{l}1.9 \pm 1.2(5) \\
1.3 \pm 0.8(8) \\
1.5 \pm 0.9(10)\end{array}$ \\
\hline
\end{tabular}

Table I ${ }^{47} \mathrm{Ca}$ absorption from each type of meal in the three groups of subjects studied ${ }^{1}$

${ }^{1}$ All results are means \pm 1 standard deviation. The number of subjects studied is indicated in brackets. 


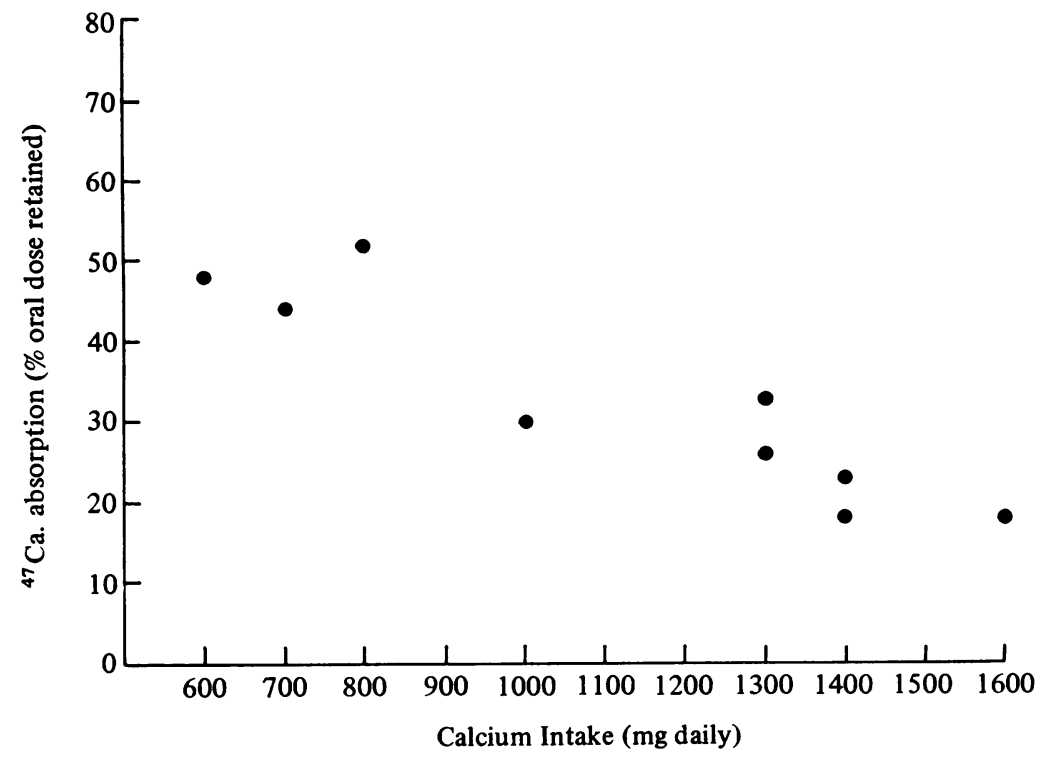

Fig. 2 The absorption of ${ }^{47} \mathrm{Ca}$ from the medium-chain triglyceride meal by nine postgastrectomy subjects in relation to their normal dietary calcium intake.

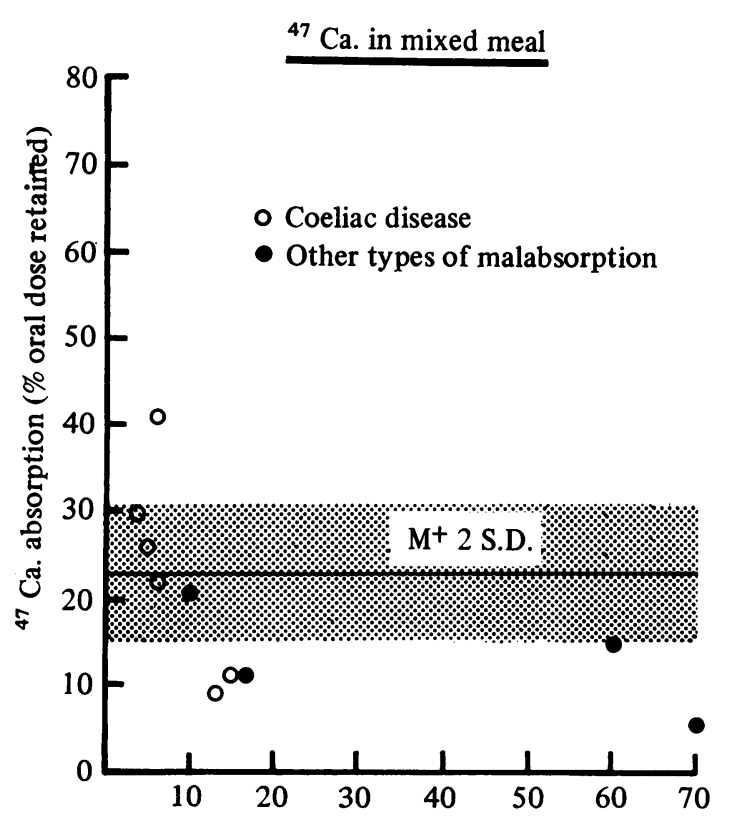

Faecal fat (gm. daily)

Fig. 3 Absorption by patients with malabsorption of ${ }^{4} \mathrm{Ca}$ taken in a milk and porridge breakfast, in relation to their faecal fat excretion. The range $(M \pm 2 S D)$ in normal subjects is indicated. gastrectomy $(\mathrm{n}=15, \mathrm{t}=4.77, \mathrm{P}<0.001)$ but not in patients with malabsorption $(\mathrm{n}=6, \mathrm{t}=0.39)$. However, when assessed by three-hr ${ }^{47} \mathrm{Ca}$ plasma levels, patients with malabsorption did appear to absorb calcium better from the meal with mediumchain than from the meal mixed with long-chain triglyceride $(\mathrm{n}=6, \mathrm{t}=3.07, \mathrm{P}<0.05)$, although this result may imply a faster rate of absorption from the medium-chain triglyceride meal rather than a significant difference in total absorption. In all other groups, statistical analysis of plasma ${ }^{47} \mathrm{Ca}$ levels indicated similar differences in absorption to those shown by the whole body counter.

Three patients had osteomalacia, and in two of these, both suffering from idiopathic steatorrhoea, it was possible to re-test calcium absorption from the same type of meal after taking by mouth $1.25 \mathrm{mg}$ of calciferol daily for two months. Calcium absorption rose to very high levels in both cases, from $16 \%$ to $77 \%$ and from $26 \%$ to $86 \%$ respectively.

Mean calcium absorption measured by the whole body counter was higher in patients with a partial gastrectomy than in normal subjects from meals with no added fat $(P<0.05)$ and with added medium-chain triglyceride $(P<0.01)$, but not from the meal with added long-chain triglyceride. Plasma ${ }^{47} \mathrm{Ca}$ levels also showed significantly greater calcium absorption by patients with a partial gastrectomy from the meal with no added fat $(P<0.01)$ and with added medium-chain triglyceride $(P<0.001)$. 
A retrospective dietary history was taken in nine of the 17 patients with a partial gastrectomy. These nine patients were selected solely on their availability for interview at the end of the study. Figure 2 shows that there was a significant inverse correlation between calcium intake and calcium absorption from the medium-chain triglyceride meal $(r=0.91$, $\mathbf{P}<0.01$ ). There was a similar relationship between calcium intake and calcium absorption from the other types of meals.

The relationship between ${ }^{47} \mathrm{Ca}$ absorption and faecal fat excretion in the patients with malabsorption is shown in Figure 3. The mixed meal containing medium-chain triglyceride was chosen as most results were available using this meal. There is a clear relationship between calcium absorption and the degree of steatorrhoea. All patients with a daily faecal fat excretion of more than $10 \mathrm{~g}$ absorbed calcium poorly. Each of the three patients with normal or almost normal fat absorption absorbed calcium normally.

\section{Discussion}

Different dietary fats may either stimulate or depress calcium absorption (Vérzar and McDougall, 1936). Southgate, Widdowson, Smits, Cooke, Walker, and Mathers (1969) found that in young infants fed on certain proprietary milk feeds, unabsorbed fat appeared to interfere with the absorption of calcium. In an earlier study, Steggerda and Mitchell (1951) failed to find any difference in the calcium balance of normal adult human subjects on high and low butter-fat diets. The influence of other fats on calcium absorption in adult man has not been studied.

Animal experiments reviewed by Steggarda and Mitchell (1951) and earlier by Vérzar and McDougall (1936) are not all in agreement, but it would appear that calcium absorption would be least favoured by triglycerides containing fatty acids with long-chain lengths and a high degree of saturation. More recent animal experiments using radioactive calcium confirm this (Kehayoglou et al, 1968; Tadayyon and Lutwak, 1969). For this reason we chose to compare, in man, the effects of a triglyceride composed of long-chain saturated fatty acids with those of a triglyceride composed of medium-chain length fatty acids.

Calcium was absorbed in normal subjects more readily from the meal mixed with medium-chain triglyceride than from the meal containing longchain triglyceride. This difference was even more marked in patients with a partial gastrectomy. This may be because in subjects with an intact stomach, sitting erect as was usual during the test, ${ }^{47} \mathrm{Ca} \mathrm{Cl}_{2}$ may not enter the small intestine at the same time as the fat. Different rates of emptying of the lower aqueous and upper lipid phases of a mixed meal have been observed (Wiggins and Dawson, 1961; Chang, McKenna, and Beck, 1968). In patients with rapid gastric emptying, the fats will be more likely to enter the small intestine mixed with the ${ }^{47} \mathrm{Ca} \mathrm{Cl}_{2}$ and other components of the aqueous phase of the meal. In normal subjects, on the other hand, the ${ }^{47} \mathrm{Ca} \mathrm{Cl}_{2}$ in the aqueous component of the meal might be expected to enter the small intestine and be at least partly absorbed before the fat had left the stomach (Chang et al, 1968).

The increased calcium absorption found in patients after gastrectomy, in comparison with normal subjects, was an unexpected finding. Deller (1966) found decreased absorption of ${ }^{47} \mathrm{Ca}$ given in $200 \mathrm{ml}$ milk to four patients with postgastrectomy steatorrhoea but normal absorption in most other patients after gastrectomy. Arman, Nilsson, and Reizenstein (1961) also found normal calcium absorption in seven patients with a partial gastrectomy when the ${ }^{47} \mathrm{Ca} \mathrm{Cl}_{2}$ was administered with $50 \mathrm{ml}$ of milk, but did find hyperabsorption of ${ }^{47} \mathrm{Ca} \mathrm{Cl}_{2}$ taken in water. They claimed that a low calcium intake, which can lead to a compensatory increase in calcium absorption (Spencer, Lewin, Fowler, and Samachson, 1969), could not account for their findings. In our nine patients from whom a dietary history was available the calcium intake was normal (1,100 mg daily) although mean calcium absorption was high. We therefore agree with Arman et al (1961) that the calcium hyperabsorption is unlikely to be due to a low calcium intake, although Fig. 2 demonstrates the influence of calcium intake on calcium absorption. Perhaps the calcium hyperabsorption after partial gastrectomy is a reflection of calcium deficiency, and this problem requires further study.

In patients with malabsorption, absorption of calcium from all types of meal was depressed in the patients with increased faecal fat excretion (Fig. 3). When ${ }^{47} \mathrm{Ca}$ is given unmixed with food, calcium absorption is often normal in patients with steatorrhoea (Agnew et al, 1969) and in seven patients with untreated idiopathic steatorrhoea we found no relationship between the degree of steatorrhoea and the absorption of ${ }^{47} \mathrm{Ca} \mathrm{Cl}_{2}$ given in water, unmixed with food (Agnew and Holdsworth, unpublished observations). Many components of the meal could be responsible for the depressed calcium absorption found in patients with steatorrhoea, including the milk fat or the phosphate and phytate in the porridge. It was disappointing to find that in malabsorptive states medium-chain triglycerides were not able to overcome the inhibition of calcium absorption produced by other dietary constituents, although the plasma ${ }^{47} \mathrm{Ca}$ determinations suggested that the 
medium-chain triglyceride may be having some beneficial effect on calcium absorption.

Calcium absorption in any one individual is affected by a wide variety of influences. Our study only set out to define the influence of fat on calcium absorption from a particular type of meal. The stimulation of calcium absorption found when the long-chain was replaced by the medium-chain triglyceride is of physiological interest, and possible reasons for this have been discussed elsewhere (Kehayoglou et al, 1968). It is also of some relevance to therapy, as replacement of dietary long-chain by medium-chain triglyceride should facilitate absorption of dietary calcium in patients with steatorrhoea. In malabsorptive states, however, adequate correction of any vitamin D deficiency must always be the mainstay of treatment if there is osteomalacia. Observations reported in this paper and elsewhere show that this will initially lead to hyperabsorption of calcium. Calcium supplements should be given with the vitamin $\mathrm{D}$, and it is clear from this and previous studies (Agnew et al, 1969) that if these are to be effectively absorbed they should be given to the fasting subject and not taken with meals.

We are grateful to all our subjects for their cooperation, and to Dr A. M. Dawson for allowing us to include some of his patients in this study. We wish to thank Dr R. V. Austen and Mr J. C. G. Nisbet of Unilever Ltd for preparing and analysing the palm oil, and Mr B. Roe of Cadbury Bros Ltd for the supply and analysis of Marvel dried milk. Our dieticians gave invaluable help, Miss E. C. Bateman
(Royal Free Hospital) in preparing the meals, and Miss H. Burrows (St Leonard's Hospital) in taking the dietary histories. We also wish to thank Miss P. Middleton for technical assistance. The work was supported by a grant from the Research Committee of the North East Metropolitan Regional Hospital Board.

\section{References}

Agnew, J. E., Kehayoglou, A. K., and Holdsworth, C. D. (1969). Comparison of three isotopic methods for the study of calcium absorption. Gut, 10, 590-597.

Arman, E., Nilsson, L. H., and Reizenstein, P. (1970). Studies in the dumping syndrome VI calcium deficiency after partial gastrectomy. Amer. J. dig. Dis., 15, 455-462.

Chang, C. A., McKenna, R. D., and Beck, I. T. (1968). Gastric emptying rate of the water and fat phases of a mixed test meal in man. Gut, 9, 420-424.

Deller, D. J. (1966). Radiocalcium absorption after partial gastrectomy. Amer. J. dig. Dis., 11, 10-19.

Kehayoglou, A. K., Williams, H. S., Whimster, W. F., and Holdsworth, C. D. (1968). Calcium absorption in the normal, bile duct ligated and cirrhotic rat, with observations on the effect of long- and medium-chain triglycerides. Gut, 9, 597-603.

Southgate, D. A. T., Widdowson, E. M., Smits, B. J., Cooke, W. T., Walker, C. H. M., and Mathers, N. P. (1969). Absorption and excretion of calcium and fat by young infants. Lancet, 1, 487-489.

Spencer, H., Lewin, I., Fowler, J., and Samachson, J. (1969). Influence of dietary calcium intake on $\mathrm{Ca}^{47}$ absorption in man. Amer. $J$. Med., 46, 197-205.

Steggerda, F. R., and Mitchell, H. H. (1951). The calcium balance of adult human subjects on high- and low-fat (butter) diets. J. Nutr., 45, 201-211.

Tadayyon, B., and Lutwak, L. (1969). Effects of dietary triolein, tripalmitin and L-phenylalanine on calcium absorption in the rat. Proc. Soc. exp. Biol. (N.Y.), 130, 978-979.

Vérzar, F., and McDougall, E. J. (1936). Absorption from the Intestine, p. 105. Longmans, Green, London.

Wiggins, H. S., and Dawson, A. M. (1961). An evaluation of unabsorbable markers in the study of fat absorption. Gut, 2 , 373-376. 